\title{
Rendering ECR in Subtitles: A Case Study of the Traditional Chinese Martial Arts Films
}

\author{
DENG Gaosheng ${ }^{1,2}$ \\ ${ }^{1}$ Xianda College, Shanghai International Studies University, School of Foreign Languages, Shanghai, China \\ ${ }^{2}$ City University of Hong Kong, Department of Linguistics and Translation, Hong Kong, China \\ Correspondence: DENG Gaosheng, Xianda College, Shanghai International Studies University, School of \\ Foreign Languages, 200080, Shanghai, China. E-mail: 18256132505@163.com
}

Received: November 2, 2018

Accepted: December 2, 2018

Online Published: December 31, 2018

doi:10.5539/ach.v11n1p31

URL: http://dx.doi.org/10.5539/ach.v11n1p31

\begin{abstract}
The traditional Chinese martial arts film is a special type of mass media which reflects the Chinese culture, and it comes into vogue due to the popularity of martial arts fiction. For foreign audiences, watching the traditional Chinese martial arts film, they rely heavily on subtitles to understand the plot and the specific Chinese culture. However, it is not easy to produce readable subtitles. Jan Pedersen, defines the specific cultural terms as "Extralinguistic Cultural References (ECR)", and puts forward a systematic theory. In this paper, the theory of Pedersen is been used to render ECRs in subtitles of the traditional Chinese martial arts films. The purpose of this paper is to attract people's attention to the studies of translation of ECRs of subtitles, and to contribute a small effort to the "going out" initiative of Chinese culture.
\end{abstract}

Keywords: Subtitling, the Traditional Chinese Martial Arts Films, Extralinguistic Cultural Reference, Translation Strategies

\section{Introduction}

Foreign films are popular among audience, especially for young people, since they are curious about the outside world, and are easily attracted by the special effects and exotic cultures. With the popularity of foreign films in China, Chinese films also have many fans in the world, especially for Kung fu films, they are very popular in the world and has become a label of Chinese film.

"Both as one of the subcategories of martial arts films" (Chen, 2006, p. 6), the popularity of the traditional Chinese martial arts films are relatively low compared with the modern Kung $f u$ films. One of the reasons is that the traditional Chinese martial arts films contain many cultural terms which are language barriers for audience to understand.

Generally, all films need to deal with the problems of language barriers when they are released in foreign countries and regions. Two common ways are used to copy with it, one is dubbing, the other is subtitling. Subtitling is regarded as a more commonly used strategy to overcome language barriers in the audiovisual field. Its benefit is twofold, on the one hand, it keeps the original dialogue without change actor's voice. On the other hand, it is a simpler and cheaper way with only subtitles appearing at the bottom of the screen. These advantages of subtitling highlight its role in introducing films to other countries and regions. The significance of subtitling in cultural exchange in the world can't be underestimated.

The techniques of subtitling have been improved a lot in recent years, so as the relevant studies with numerous achievements. In terms of the cultural references in subtitles, Jan Pedersen defined them as "Extralinguistic Cultural Reference (ECR)", and came up with "seven influencing parameters" (Pedersen, 2011, pp. 106-115) and several translation strategies (pp. 77-97). The theory of ECR is a systematic theory, but this theory is rarely mentioned in the field of academic studies in China, only three papers mentioned it (Note 1). In this paper, the theory of ECR will be used in analyzing the subtitles of traditional Chinese martial arts films. 


\section{Overview of Subtitling}

Subtitling is a process of providing synchronous captions for film and television dialogue. For subtitles, they are usually "condensed written translations of original dialogue which appear as lines of text" (Luyken, 1991, p. 31), which means that subtitles are the words appearing at the bottom of the screen.

"The space on screen available for the text of a subtitle is severely limited" (Luyken, 1991, p. 42). In other words, subtitling is restricted by space, which means that subtitling is restricted to the size of the screen and the number of words allowed in one line of subtitles. Subtitles should be short with few words in one line, because too many words will occupy too much space, which will affect the watching experience. The number of lines on one screen is another issue. Subtitle generally occupies "a maximum of two lines" (Au, 1991, p. 337), containing no more than "forty English letters and spaces" (Luyken, 1991, p. 43) or "thirteen Chinese characters" (Au, 1991, p. 337) per line on one screen to avoid being crowded.

Subtitling is also restricted by time. The time constraint of subtitling is mainly embodied in two aspects: the first one is the duration of time of the dialogue and the picture, the second one is the time for audiences to read the subtitle. "If a subtitle is retained on screen during a short or scene change it will result in an effect known as 'overlapping' which is detrimental to the aesthetics and intelligibility of the subtitle" (Luyken, 1991, p. 45). Audiences may need different duration of time to read the same subtitle. "More than $90 \%$ read a full two-line subtitle in less than four seconds, and some need only half that time" (Ivarsson \& Carroll, 1998, pp. 63-64). This requires the subtitler to give an appropriate duration of time of subtitles to appear on the screen for all viewers to read.

\subsection{Subtitling Studies at Abroad}

"Almost since the invention of film, efforts have been made to convey the dialogue of the actors to the audience" (Ivarsson \& Carroll, 1998, p. 9). As time goes by, scholars from all over the world devote efforts to subtitling studies. "More and more translation scholars have conducted academic studies on the subject matter and produced fruitful results: Luyken, 1991; Dollerup \& Lindegaard, 1993; Gottlieb, 1997; Ivarsson \& Carroll, 1998; Karamitroglou, 2000; Gambier \& Gottlieb, 2001; Orero, 2004; just to name a few" (Fong \& Au, 2001, p. vii).

Theories and strategies are generated in new perspectives. That is to say, subtitling can't be researched merely in linguistic and technical aspects, but should be put into a wider context, namely, cultural background and extratextual influencing factors. As for culture elements in subtitling, there are some effective subtitling theories and strategies formed from experience, but it still lacks systematic theories.

Many scholars contributed a lot to the studies of subtitling. Ivarsson concluded the history of subtitling (1998, pp. 9-20), he put forward the principles of subtitling for television (pp. 63-66), provided the basis for further studies of the subtitle translation. Gottlieb highlighted the prevalence of English and the popularity of subtitling in cinema (2004, pp. 83-86), he discussed the problem of preserving the original spirit (2009, pp. 22-23).

Jan Pedersen put forward the definition of Extralinguistic Culture-bound Reference (2005), abridged as Extralinguistic Cultural Reference in 2007 and 2011, and he used it to refer to the cultural elements that need to be considered in subtitling. He concluded several main strategies for translation of ECRs, such as Retention, Specification, Direct translation, Generalization, Substitution, Omission and Official Equivalent (2011, pp. 159-169). Seven parameters -- Transculturality, Extratextuality, Centrality ("Centrality of reference" in How is culture rendered in Subtitles (2005, p. 12)), Polysemiotics ("Intersemiotic redundancy" in 2005), Co-text, Media-specific constraints and The effects of the subtitling situations ("Paratextual considerations" in 2005) (pp. 105-115) -- that have influence on the subtitler's choice of translation strategies.

\subsection{Subtitling Studies in China}

Compared with Western countries, China's studies of subtitling started much later. There is almost no systematic theory about subtitling until 1990s when some scholars began to publish articles about how to improve the quality of subtitles in China.

Kenneth K. L. Au, discussed the process of subtitling from his experience in Television Broadcasts Limited (TVB). He proposed the constraints of subtitling from perspectives of time and space (1991, pp. 337-338), put forward principles of subtitling in Chinese, for example, kept the exclamation point and interrogation point and deleted comma and full comma (p. 339). He also argued the difficulties of translating cultural references and put forward translation strategies (pp. 344-345).

Zhang Chunbo proposed that film is a screen art as well as a sound art (1998, p. 50). He focused on Nida's Functional Equivalence, and suggested that subtitler should put target audiences as the center and consider their 
language levels to produce readable subtitles (p. 50). Besides, he also paid attention to Domestication in subtitling, he used the translation strategy of Domestication to pursue functional equivalence. Referring to dealing with cultural items, he suggested that Domestication is to replace the source cultural items with target ones so as to help target audiences to understand the original meaning (pp. 50-53). Moreover, he also said that if audiences have enough knowledge of the source culture, Literal translation may add more authentic feelings in subtitle.

Li Yunxing studied subtitling from the perspective of discourse translation (2001, p. 38). He analyzed the features of subtitling in term of time-space constraints, informative function and cultural factors (p. 38) and he described the cultural factors as culture-specific words (p. 39), and focused on the translation strategies of these culture-specific words.

Zhao Chunmei engaged in the work of subtitle translation of foreign films in the international department of CCTV (China Central Television). She pointed out four main conflicting demands in the process of subtitling (2002, p. 49). In her opinion, foreign film, as an important way of the exchange of cultures, contains many cultural contents and specific cultural images which are difficult to be retained in target language (p. 50). Therefore, she put forward her translation strategies in subtitling from the perspective of Foreignization (p. 50).

\section{ECRs in Traditional Chinese Martial Arts Films}

\subsection{Introduction to Traditional Chinese Martial Arts Film}

Martial arts film is a sub-genre of action film, it is "the oldest genre in the Chinese cinema that has remained popular to the present day" (Teo, 2009, p. 1). It contains numerous martial arts fights between characters. These fights are usually the film's primary attractiveness and entertainment values. They are also methods of storytelling and reflections of character's characteristics.

In China, martial arts film is commonly divided into two subcategories: the traditional Chinese martial arts film (also called 武侠片 or Wuxia period film which features sword fighting in ancient costume) and the modern Kung fu film (功夫片 or Kung fu movie which is full of scenes of beating and kicking in modern costume, best epitomized in the films of Bruce Lee). The traditional Chinese martial arts film comes into vogue due to the thousands of years popularity of martial arts fiction (also called 武侠小说or Wuxia novel which dates back to AD 618-907 and it is one of the few surviving Chinese literary forms which can claim a direct link with traditional popular literature). For example, the martial arts fictions of Louis Cha and Gu Long directly led to the prevalence of the traditional Chinese martial arts film.

The traditional Chinese martial arts film is a special type of film that reflects the traditional Chinese cultures. As a type of film art, the traditional Chinese martial arts film has already been deeply "marked with Chinese personality" (Chen, 2002, p. 219). In fact, it was not until the 1920s that the traditional Chinese martial arts film appeared in cinema (The film Burn the Honglian Temple 《火烧红莲寺》 is considered as the first traditional Chinese martial arts film), and from then on its popularity does not diminish. On the one hand, the traditional Chinese martial arts film contains numerous fascinating fighting scenes that attract audiences' attention. On the other hand, the culture of "Xia" (which is a noun to denote a breed of male and female warrior figures whom we may loosely call 'knights-errant') is also "a reflection of Chinese culture" (Chen, 2002, pp. 216-220), and it has influenced the Chinese national character. The traditional Chinese martial arts film integrates the Chinese literature, ethics, philosophy, aesthetics, religion and martial arts. It is an art form that shows the essence of Chinese national culture and national spirit.

The traditional Chinese martial arts films have numerous Chinese audiences from "all social strata and is popular not only in China" (Jia, 2005, p. 1), but also in many overseas Chinese communities, "even all around the world" (Teo, 2009, p. 12).

\subsection{Introduction to Extralinguistic Cultural Reference}

\subsubsection{Definition of Extralinguistic Cultural Reference}

During the process of subtitle translation, there are many cultural items in the subtitles that may lead to translation problems. This kind of item is called "Extralinguistic Cultural-bound Reference (ECR)" by Jan Pedersen (2005, p. 2), abridged as "Extralinguistic Cultural Reference" (2007, p. 30). Jan Pedersen put forward the Extralinguistic Culture-bound Reference (ECR) in the EU-High-Level Scientific Conference in 2005, and he used it to refer to the cultural elements that need to be considered in subtitling. He defined ECR as: 
culture-bound linguistic expression("Cultural linguistic expression" in 2011), which refers to an extralinguistic entity or process, and which is assumed to have a discourse referent that is identifiable to a relevant audience as this referent is within the encyclopedic knowledge of this audience.

(2005, p. 2)

In general, ECRs refer to culture-loaded words. For example, proper names of places and people, expressions which contain religions, traditional culture and customs, and so on.

\subsubsection{ECRs in the Traditional Chinese Martial Arts Films}

The traditional Chinese martial arts films are treasures of Chinese culture. "It has a large amount of audiences at home" (Jia, 2005, p. 1) and "abroad" (Teo, 2009, p. 12), and "plants a seed of heroic dream" (Chen, 2002, p. 14) in almost every audience's mind. When translating subtitles of the traditional Chinese martial arts films, we may find that some cultural items are difficult to translate, like names and nicknames of people, ancient Chinese official titles, ancient Chinese weapons and Chinese food. Actually, these items are ECRs in the traditional Chinese martial arts films.

\subsection{Influencing Parameters of Translation of ECR}

Generally, in real situations, the translator may adopt more than one strategy to translate cultural references, and correspondingly there may be many factors that influence the translator's choice-making. Jan Pedersen called these factors as "parameters" (2005, p. 10). Parameter refers to something that decides or limits the way in which something can be done. Clearly, parameters are the factors that influence the choice of subtitling strategies. In Pedersen's opinion, seven most important parameters are often considered, namely, "Transculturality, Extratextuality, Centrality, Polysemiotics, Co-text, Media-specific constraints and The effects of the Subtitling Situation" (2011, pp. 105-115).

\subsubsection{Transculturality}

Transculturality refers to the familiarity of an ECR or "how well known an ECR is" (Pedersen, 2011, p. 106). It is the most basic influencing parameter in subtitling which discusses how cultures in the modern world are extremely "interconnected and entangled with each other" (Welsch, 1994, p. 198). ECRs have gradually stepped out from one culture to another, becoming more familiar to people on a global scale. In view of the degree of familiarity of an ECR to a culture, Pedersen divided the level of transculturality into three degrees: "transcultural ECRs, monocultural ECRs and microcultural ECRs" (2011, p. 107).

Transcultural ECRs refer to ECRs that belong to a third culture, but are known to both ST and TT audiences. Monocultural ECRs refer to ECRs that belong to the source culture which are less familiar to TT audiences. Microcultural ECRs refer to ECRs from the source culture, while they are too specialized or too local to be known to the majority of ST and TT audiences.

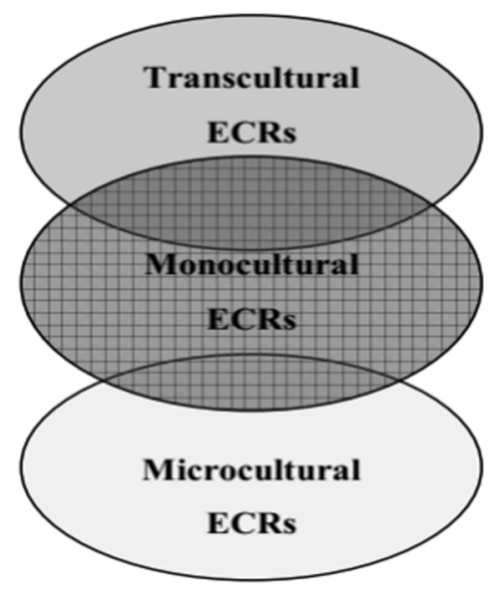

(Pedersen, 2011, p. 107)

\subsubsection{Extratextuality}

Extratextuality refers to something existing outside the text. This parameter has to do with whether an ECR exists outside the ST or not. If it does, it is "Text External" (Pedersen, 2011, p. 110). A Text External is an ECR 
that exists in a culture and it is independent from the text. Conversely, if an ECR exists in the text, it is Text Internal.

Transcultural ECRs, monocultural ECRs and microcultural ECRs belong to Text External while microcultural ECRs belong to "Text Internal" (pp. 110-111). Sometimes, a Text External ECR can be turned into a Transcultural ECR, which is more conducive to ECRs translation. An originally Text Internal ECR may also become a Transcultural ECR through the process of intertextuality, if it is successful.

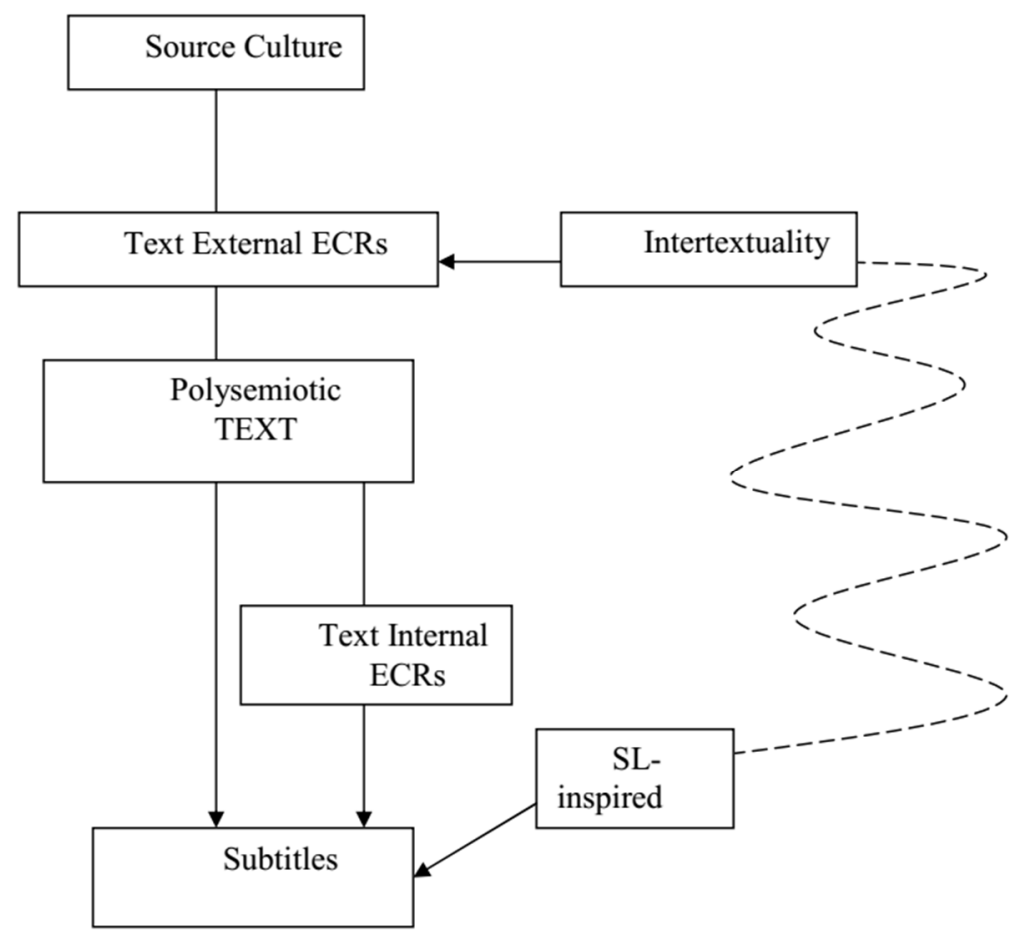

(Pedersen, 2011, p. 111)

\subsubsection{Centrality}

Centrality refers to the importance of an ECR. It involves multiple levels in subtitling, while considering the centrality of an ECR in the source subtitles, we have to analyze it at least from two levels: the macro level and micro level. If an ECR is central on the macro-level, it may typically be the subject matter, or at least a very important theme of the film or TV programme. It would then be more or less impossible to render it by using any other strategies than Retention or Official Equivalent. However, if an ECR does not have a great relationship with the film plot, it could be peripheral, and the strategy of Omission may be used.

\subsubsection{Polysemiotics}

Polysemiotics refers to the "interplay between channels" (2011, p. 113) or the degree of overlap of different semiotic information. Subtitling, unlike literary translation or dubbing, it adds information rather than substitutes the ST with TT. Gottlieb stated that there are four semiotic channels which convey messages of the source texts, namely, "the non-verbal visual channel (i.e. the picture), the non-verbal audio channel (i.e. music and sound effects), the verbal audio channel (i.e. the dialogue) and the verbal visual channel (i.e. captions and signs)" (1997, p. 143), all of them carry different semiotic messages. In films, all the four channels carry semiotic information and there are overlaps between them, i.e., the "intersemiotic redundancy" (p. 143).

"Gottlieb's explanation of intersemiotic redundancy is closely connected to Polysemiotics" (Pedersen, 2011, p. 113). The polysemiotics may be a more general notion to refer to the "interplay between more complex channel" (p. 113). It discusses the amount of guidance the TT audience needs. For example, if an ECR is referred in the dialogue while it can also be seen in the picture, it may be enough to refer it by using a pronounce in the subtitles. 


\subsubsection{Co-text}

Co-text refers to the "overlapping information in the context" (Pedersen, 2011, p. 114). In a film, an ECR may occur several times, and there is no need to translate them each time. If an ECR has been rendered or explained before, the translator does not have to translate it again.

\subsubsection{Media-specific Constraints}

There are two constraints for subtitling, the first one is the "semiotic switch" from the spoken language to the written word, the other one is the "restricted factors" of time and space (Pedersen, 2011, p. 115). Semiotic switch means that the text gets somewhat formalized in the transfer from SL to TL. Restricted factors refer to that subtitling is restricted by the time, the time constraint of subtitles is mainly embodied in two aspects: the first one is the duration time of the dialogue and the picture, the second one is the amount of time for audiences to read the subtitles. Subtitling is also restricted by the space, for example, the number of lines on one screen. A subtitle generally occupies "a maximum of two lines" (Au, 1991, p. 337), containing no more than "forty English letters and spaces" (Luyken, 1991, p. 43) or "thirteen Chinese characters" (Au, 1991, p. 337) per line on one screen to avoid being crowded.

\subsubsection{The Effects of the Subtitling Situation}

There are many factors that influence the subtitling despite the linguistic and cultural parameters, for example, personality of the subtitler, the guidelines of film companies and special requirements of broadcasters. During the process of subtitling, the subtitler needs to consider the goal and the genre of the film. The genre is one of the best clues which tells the goal of the text. For instance, if a film belongs to the action comedy, the goal of the subtitle is to achieve the purpose of amusement.

The age of audiences is also an important guidance for subtitlers. For adults, some ECRs could be considered as transcultural ECRs, so we can use its Official Equivalent. While, for children, Specification and Generalization may suit the educational levels of the audiences better.

\section{Analysis of Subtitles of New Dragon Gate Inn and Flying Swords of Dragon Gate}

New Dragon Gate Inn, a remake of Dragon Gate Inn (1967), was a traditional Chinese martial arts film produced by Tsui Hark. New Dragon Gate Inn represents a milestone in the traditional Chinese martial arts films and serves as the peak in the New School martial arts films (Note 2). Flying Swords of Dragon Gate was also a remake of Dragon Gate Inn (1966) and New Dragon Gate Inn (1992), and was another traditional Chinese martial arts film directed by Tsui Hark in 2011. Both New Dragon Gate Inn and Flying Swords of Dragon Gate are typical traditional Chinese martial arts films with many Extralinguistic Cultural References (ECRs) that are difficult to translate. This chapter aims to contribute to the studies of subtitle translation of the traditional Chinese martial arts films by discussing the applicable strategies with regard to these two films.

\subsection{Analysis of Subtitles of People's Name}

Analyzing people's name in subtitles of New Dragon Gate Inn and Flying Swords of Dragon Gate, we may find that although the gap between two films' shooting times is about twenty years, the strategies for translating names are surprisingly almost the same, they both follow the strategy of Transliteration.

Transliteration is the process of expressing the sound of how a word is pronounced in the source language in the alphabet of the target language. Virga and Khudanpur define transliteration as "one tries, when writing foreign names in one own language, to preserve the way it sounds" (p. 57). Transliteration is commonly used in translating names, and it is also the main way to translate characters' names in literary works (Wang, 2007, p. 188 ) as well as subtitles. Names are not like nicknames, though names also contain certain cultural connotations, which are mostly used as codes. Chinese language belongs to Sino-Tibetan languages while English is part of Indo-European languages. Unlike English which is made up of Latin alphabets, the Chinese language consists of monosyllable's characters, and its syllables correspond to the pronunciation of any languages. That makes it possible to be transliterated into other languages.

Transliteration is mostly used for the translation of names. The translator of New Dragon Gate Inn comes from Hong Kong and speaks Cantonese, so the translator used locally adapted Cantonese transliteration system to render names, for example: Tsao Siu Yan (曹少钦) and Chow Wai-on (周淮安). The translator of Flying Swords of Dragon Gate is from mainland China, so the translator uses putonghua pinyin to translate the names, for instance: Zhao Huai'an (赵怀安), Ling Yanqiu(凌雁秋), Yu Huatian(雨化田). 


\subsection{Analysis of Subtitles of Nicknames}

Nickname is the substitute of the proper name of a familiar person, place, or thing. In Chinese culture, nicknames are frequently used within a community among relatives, friends and neighbors. Nickname often conveys character's personality or the author's preference. Many traditional Chinese martial arts films are famous for their beautiful integration of traditional Chinese culture and characters' nicknames. Apart from replacing a ST ECR with a similar TT ECR, there are some examples in which the translator replaces ST ECRs with their characteristics or translates part of their nicknames literally.

In New Dragon Gate Inn, there is a nickname called “一抹红” which expresses the man's feature that he has a red point in his forehead. In the film, this nickname was subtitled as "Ruddy", this is an example in which the translator translates it with the character's feature instead of translating the whole nickname directly. Another example is the innkeeper's nickname “金镶玉”, the literal meaning of this nickname is a piece of jade inlaid with gold. Because of the restrictive number of words in one line of subtitling, there is no room for us to explain the nickname with long sentences. In addition, it is also inappropriate to name a person with too many words. Again, the translator translates it with part of the feature of her nickname and her personal characteristic and subtitled it as "Jade King". The reason that the translator uses the word "King" may be from Jade's status of the Dragon Gate inn as the inn keeper. “小黑子”is the nickname of “J不遇”, perhaps the reason why he has this nickname is that he has dark skin, and similarly, in the film, his nickname was subtitled as "Darkie".

In Flying Swords of Dragon Gate, there is another term called “薄情郎”, which refers to unfaithful husband or heartless lover, it is used to describe a man who often changes his lover. The subtitle of it is "fickle man". "Fickle" means changeableness in affections or attachments, which fits the context, but fickle can also be used between friends.

When the leader of the West Bureau Yu Huatian came to see the Concubine Wan, Wan called him with a nickname that contains many modifiers to show her affection, namely, “心肝宝贝开心果”. The direct translation of this nickname may occupy eight words, and it will be too many words for a nickname in subtitle. What's more, there is a correspondent in the target language that contains similar meaning and used in similar context, namely, treasure of my heart. At this time, the subtitle of the dialogue is the replacement of the correspondent in the target language.

\subsection{Analysis of Subtitles of Ancient Chinese Official Titles}

There are phenomena of mismatches of translations of ancient Chinese official titles in the traditional Chinese martial arts films. Translator's ignorance of cultural differences and these expressions' importance are two main causes. Indeed, there are cultural overlaps between languages, and in this case, we may simply replace a ST ECR with a correspondent in TT. Substitution means replacing culture with culture. This strategy involves "removing the ST ECR and replacing it with something else, either a different ECR from the SC or the TC, or something completely different that fits the situation". (Prdersen, 2005, p. 6)

In New Dragon Gate Inn, there is an ancient Chinese official title called “东厂督公”. “东厂” is a secret agency established in Ming Dynasty which is similar to the supervisory organ, secret service and secret police station in modern society. In New Dragon Gate Inn, it was subtitled as "East Chamber". The word "chamber" refers to a deliberative, legislative, administrative or judicial assembly, for example, the upper chamber in America is the senate. In Flying Swords of Dragon Gate, “东厂”was subtitled as "East Bureau". The word "Bureau" refers to an administrative unit of the government. Although both "Chamber" and "Bureau" do not contain the meaning of secret service, but the use of "Bureau" connects us to "Federal Bureau of Investigation (FBI)" while the word of "Chamber" always reminiscent of the chamber of commerce. In this case, "Bureau" may be a better choice.

“督公”means the senior officer of “东厂”, and in New Dragon Gate Inn, “东厂督公” was subtitled as “head of the East Chamber" and "Your Excellency". "Head of the agency" does contain the same meaning with senior officer, and for "Your Excellency", it is a respectful form of address of senior officials, which also fits the context. The translations of “督主” (“督公”in New Dragon Gate Inn with same meaning) are“the head of East Bureau" and "You Highness". From the discussion above, we know that "the head of East Bureau" fits the context. However, "Your Highness" is a title used to address a prince or princess in formal situation. Since the term is used as a respectful form of address of the head of the agency who is not a member of Royal family, the subtitle is a mismatch of the dialogue.

Besides “东厂督公”, some other ancient Chinese official titles can also be found in New Dragon Gate Inn, for example, “兵部尚书”, which is the ancient title of the commander of the national military force. The translation of this title is "Military Secretary". The Military Secretary is a senior officer in the British army, it was originally 
established as the Military Secretary. Later it changed to the Secretary of State for War in 1904. In 1964 it became to the Secretary of State for Defence. From the translation, we can find that the translator deliberately used the old title of "Military Secretary" rather than "the Secretary of State for Defence" to replace the ancient Chinese official title “兵部尚书”. This is a good try to render the ST ancient official title with a corresponding TT ancient official title.

In conclusion, when we translate the ancient Chinese official titles, the most appropriate way is to replace the ST ECRs with the correspondents in TT. Substitution means to replace ST ECR with something else, "either a different ECR from the SC or the TC, or something completely different that fits the situation" (Pedersen, 2011, p. 89). Thus, it is perhaps the most commonly used way to render ancient Chinese official titles.

\subsection{Analysis of Subtitles of Ancient Chinese Weapons}

In New Dragon Gate Inn, some of the ancient weapons can be rendered with their correspondents in TT, for example, we can simply replace “箭” with "arrow" and “镖” with "dart". These weapons are easy to translate since they have Official Equivalents. "Official Equivalents are some sort of official decision made by people in authority" (Pedersen, 2011, p. 97). Since an ECR already has an Official Equivalent, there is no need to translate it into other expressions.

Besides, there are some special weapons which only exist in ancient China, and their names are usually complicated which show their functions and features. In this case, we may divide the name of the weapon into "appearance + function + type" and follow the strategy of Direct translation to translate them word for word. For example, “梅花射日箭 (literally translated into Plum Blossom Sun Shooting Arrow)” is a kind of arrow which looks like plum blossom. Shown by its name, this arrow seems very destructive that it even can shoot the sun, which is an exaggeration. The arrow was subtitled as "Plum Blossom Sun Shooting Arrow", which is an example of following the translation strategy of dividing the name of the weapon into "appearance + function + type" and translating them word for word.

Dialogue: 梅花射日箭.

Dividing into: appearance梅花 (Plum Blossom) + function射日 (Sun Shooting) + type of the weapon箭 (Arrow).

Direct translation: Plum Blossom Sun Shooting Arrow.

Subtitle: Plum Blossom Sun Shooting Arrow.

The other one is called “凤尾箭”, this arrow was named by the appearance of its "after body” which looked like the phoenix tail. Again, the translator divided it into appearance “凤尾” (Phoenix Tail) + type of the weapon “箭” (Arrow) and translated them literally, then the name of the arrow was subtitled as "Phoenix Tail Arrow".

“犬齿倒勾箭” is a barb-like arrow with a sharp arrowhead on it which is as sharp as dog's teeth. In addition, this arrow can even turn around like a boomerang. This is a special arrow exists in ancient China. In New Dragon Gate Inn, this arrow was subtitled as "Dogs Teeth Arrow" which omitted its feature that can turn around. Since this arrow's name is not complicated and it won't occupy too much spaces on the screen, there is no need to omit its feature. In this case, it is more faithful to the original dialogue when rendering it into "Dogs Teeth Barb Arrow". As for the translation of “柳叶镖”, there is no need for us to omit the word "leaves" too. In New Dragon Gate Inn, it was subtitled as "The Willow Dart", while I think "The Willow Leave Dart" may be a better translation.

In Flying Swords of Dragon Gate, “短剑” refers to the short knife with a pointed blade used for piercing or stabbing. We first replace the type of weapon with Official Equivalent one, and translate the feature or function directly, then it may be subtitled as "dagger". As the dagger refers to a short knife, there is no need to translate it into "short dagger" like the translation in the film.

From the discussions above, we may find that translations of the weapons' names mainly follow the strategy of Direct translation, but there are also exceptions. For example, in New Dragon Gate Inn, there is a special sword. This sword contains a small sword in the main body. The dialogue of this sword is "子母剑 (literally translated into mother and son sword)", which refers to a small "son" sword within a big "mother" sword. This weapon was subtitled as "twin sword", although it implies the feature that it has two swords within one sword body, the differences of size between these two swords are omitted in the translation. Then "mother and son sword" may be a better translation of this sword's name. 


\section{Conclusion}

The traditional Chinese martial arts film is a distinct type of film in the world. It absorbs the traditional Chinese humane connotations and folk psychology, and is rooted in Chinese traditional culture. As a unique type of film, its tensely fighting scenes, touching plots and distinct swordsman's image have attract many audiences to watch not only in Asia, but also worldwide.

For the subtitles of the traditional Chinese martial arts film, we may find that it is difficult to render all the cultural terms with strategies of Transliteration, Direct translation and Substitution. Sometimes, language and cultural barriers are too difficult to overcome, and in these cases, the translation strategy of Omission may be used. However, the strategy of Omission is the last way to render cultural terms, because we omit the cultural terms as well as the Chinese culture.

Cultural exchange through films are increasing steadily and rapidly, so as the significance of subtitle translation. In the field of translation studies, subtitle translation has drawn more and more attention, especially for subtitle translation of cultural words. The above discussion gives us a clear understanding of the translation strategies of Extralinguistic Cultural Reference (ECR). Moreover, more choices are given to choose and experience to follow when we do subtitle translation of these ECRs.

\section{Notes}

Note 1. Zhang, Q. L. (2011). Translation of Extralinguistic Cultural References in Subtitling of Confucius. Movie Literature.

Li, Z. H. (2012). Translation of Extralinguistic Cultural References in Subtitling of Chinese Martial Arts Movies. Master thesis of Beijing Jiaotong University.

Dong, H. Y. (2012). A Great Work in the Field of Audio-visual Translation--A Evaluation of the Book of Subtitling Norms for Television. East Journal of Translation.

Note 2. The New School martial arts film originated in 1980s and flourished in the middle of 1990s. The most notable feature of this type of film is rewrite the plot and play a versed role in traditional Chinese martial arts films. Many of these films add a word "New" before the title of the traditional martial arts films, plus modern film special effects technology and movie stars to repackage the traditional Chinese martial arts films (Jia, 2005, p. 148).

\section{References}

Au, K. K. L. (1991). A Study of film subtitles in Hong Kong. In C. C. Liu (Ed.), The New Anthology of Translation: Commemorative Anthology for the 20th Hong Kong Translation Society (pp. 335-46). The Commercial Press (Hong Kong) Limited.

Chen, M. (2006). The History of Chinese Martial Arts film. Fengyun Shidai Publishing Company.

Chen, P. Y. (2002). The Dream of Ancient Scholars of being swordsman-Studies on the Genre of Martial Arts Fiction. New World Press.

Chen, S. (1992). The History of Chinese Martial Arts. Shanghai Joint Publishing Company.

Fong, G. C. F., \& Au, K. K. L. (2001). Dubbing and Subtitling in a World Context. The Chinese University Press.

Gambier, Y., \& Gottlieb, H. (2001). Multimedia Translation: Concepts, Practices and Research. John Benjamins Publishing Company.

Gottlieb, H. (1994). Subtitling: Diagonal Translation. Perspectives: Studies in Translation Theory and Practice, 2, 101-121.

Gottlieb, H. (1997). Subtitles, Translation and Idioms. University of Copenhagen.

Gottlieb, H. (2004). Language-political Implications of Subtitling. In P. Orero (Ed.), Topics in Audiovisual Translation (pp. 83-100). John Benjamins Publishing Company.

Gottlieb, H. (2009). Subtitling Against the Current: Danish Concepts, English Minds. In J. Diaz-Clintas (Ed.), New Trends in Audiovisual Translation (pp. 21-43). Multilingual Matters.

Ivarsson, J, \& Carroll, M. (1998). Subtitling. TransEdit.

Jia, L. L. (2005). The History of Chinese Martial Arts film. Culture and Art Publishing House.

Li, Y. X. (2001). Strategies for Translating Subtitles. Chinese Translators Journal, 38-40. 
Luyken, G. M. (1991). Overcoming Language Barriers in Television: Dubbing and Subtitling for the Europenan Audience. Manchester: European Institution of the Media.

Pedersen, J. (2005). How is Culture Rendered in Subtitles? EU-High-Level Scientific Conference Series. The Challenges of Multidimensional Translation: Conference Proceedings, 1-18.

Pedersen, J. (2007). Cultural Interchangeability: The Effects of Subtitling Cultural References in Subtitling. Perspectives: Studies in Translation Theory and Practice, 15, 30-48.

Pedersen, J. (2011). Subtitling Norms for Television: An Exploration Focusing on Extralinguistic Cultural References. John Benjamins Publishing Company.

Teo, S. (2009). Chinese Martial Arts Cinema: The Wuxia Tradition. Edinburgh University Press Limited.

Virga, P., \& Khudanpur, S. (2003). Transliteration of Proper Names in Cross-lingual Information Retrieval. Proceedings of the ACL Workshop on Multilingual Named Entity Recognition Combining Statistical and Symbolic Models, 15, 57-64.

Wang, B. Q. (2007). The Studies of Cultural Translation-the theory and practice of cultural translation (2nd ed.). Naikai University Press.

Welsch, W. (1994). Transculturality: The Puzzling form of Cultures Today (pp. 195-213). Space of Culture: City, Nation, World.

Zhang, C. B. (1998). A Preliminary Study of Film Translation. Chinese Translators Journal, 50-53.

Zhao, C. M. (2002). Translation into Chinese of Film Scripts and Scripts of TV Drama Series-Four Main Conflicting Demands. Chinese Translators Journal, 49-51.

\section{Appendix}

Abbreviations:

AVT: Audiovisual Translation

ECR: Extralinguistic Cultural Reference

SC: Source Culture

SL: Source Language

ST: Source Text

TC: Target Culture

TL: Target Language

TS: Translation Studies

TT: Target Text

\section{Copyrights}

Copyright for this article is retained by the author(s), with first publication rights granted to the journal.

This is an open-access article distributed under the terms and conditions of the Creative Commons Attribution license (http://creativecommons.org/licenses/by/4.0/). 